\title{
Niños y niñas escolarizadas según los libros de dos maestras argentinas, años 1930
}

Schoolarized Children According to the Books by Two Argentine Female Teachers, 1930 s

Meninos e meninas escolarizadas segundo os livros de duas mestras argentinas, anos 1930

Paula Caldo* iD orcid.org/0000-0002-4254-4159

\section{Micaela Pellegrini-Malpiedi** (iD) orcid.org/0000-0002-2124-6021}

Para citar este artículo: Caldo, P. y Pellegrini-Malpiedi, M. (2021). Niños y niñas escolarizadas según los libros de dos maestras argentinas, años 1930. Revista Colombiana de Educación, 1(82), 387-410. https:// doi.org/ 10.17227/rce.num82-10929

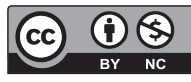

Recibido: 14/12/2019

Evaluado: 06/08/2020

$25 / 08 / 2020$

$11 / 08 / 2020$

* Doctora en Historia y Prof. y Lic en Historia. Unidad Ejecutora en Red Investigaciones Socio Histórica Regionales, Universidad Nacional de Rosario, Consejo Nacional de Investigaciones Científicas y Técnicas (ISHIR-UNR/CONICET). Correo: paulacaldo@gmail.com.

** Doctora en Ciencias de la Educación (UBA) y Lic y Prof. en Ciencias de la Educación (UNR). Unidad Ejecutora en Red Investigaciones Socio Histórica Regionales, Universidad Nacional de Rosario, Consejo Nacional de Investigaciones Científicas y Técnicas (ISHIR-UNR/CONICET). 


\section{Resumen}

Este artículo de investigación estudia cómo las maestras pensaron, definieron y (pre) escribieron acerca de sus alumnos (niños y niñas). Para ello, desde el registro de la historia cultural usamos una metodología hermenéutica interpretativa, con el fin de leer críticamente los escritos de dos educacionistas argentinas, Olga Cossettini y Herminia Brumana. La primera, una exponente del escolanovismo; la segunda, una maestra crítica distinguida por su militancia anarco-socialista. Estas mujeres acometieron la tarea de hacer propuestas pedagógicas basadas en una infancia ponderada en la práctica y alternativa al normalismo hegemónico. Este artículo aporta en la línea de estudios que recuperan los saberes docentes en perspectiva de género, esperando mostrar como resultado la destreza de las maestras para proyectar aproximaciones teóricas y prescripciones sobre las prácticas, a partir de anclajes explicativos heterogéneos. Mientras que Cossettini postuló la infancia sensible y creativa del escolanovismo, Brumana contextualizó a sus alumnos desde una lectura en clave de clases sociales y enmarcada en el problema de la desigualdad.

\section{Palabras clave}

Niños/niñas; maestras educación; género; libros
Keywords

Children; teachers; education; gender; books

\begin{abstract}
This research article studies how female teachers thought, defined, and (prescribed) wrote about their pupils. To achieve this purpose, we will use an interpretative hermeneutical methodology from a cultural history perspective, in order to make a critical reading of two Argentine female educationists: Olga Cossettini and Herminia Brumana. While the former turned out to be an exponent of the New School movement, the latter is recognized for her anarchist-socialist militancy. These women undertook the task of producing pedagogical proposals on the basis of a childhood which is analysed as an alternative to the hegemonic Normalism. This article also makes its contribution to the line of studies that recuperate teacher's knowledge from a gender perspective, hoping to exhibit the female teacher's skills to project theoretical approaches and prescriptions regarding practices, based on heterogeneous explanatory anchorages. Therefore, while Cossettini postulated New School's sensitive and creative childhood, Brumana contextualized her pupils in a social class key, and within the framework of inequality
\end{abstract}

\section{Resumo}

Este artigo de pesquisa estuda como as mestras pensaram, definiram e (pré)escreveram acerca de seus alunos (os meninos e as meninas). Para isso, desde o registro da história cultural, fazemos uso de uma metodologia hermenêutica interpretativa, visando ler criticamente os escritos de duas educadoras argentinas, Olga Cossettini e Herminia Brumana. A primeira foi uma expoente do escolanovismo, a segunda, uma mestra crítica distinguida por sua militância anarco-socialista. Essas mulheres tiveram o propósito de gerar propostas pedagógicas baseadas numa infância ponderada na prática e alternativa ao normalismo hegemônico. Este artigo contribui paraos estúdios que resgatam os saberes educativos em perspectiva de gênero. Visamos apresentar a destreza destas mestras para projetar aproximações teóricas e prescrições sobre as práticas a partir de suportes explicativos heterogêneos. Enquanto Cossettini postulou a infância sensível e criativa do escolanovismo Brumana contextualizou seus alunos a partir de uma leitura desde a perspectiva das classes sociais e enquadrada no problema da desigualdade.

\section{Palavras-chave}

Crianças; mestra; educação; gênero; livros 


\section{Introducción}

En el 2012, el filósofo Michel Serres publicó un ensayo llamado Pulgarcita. Ese personaje se presenta como el estereotipo de las nuevas generaciones que, al decir del autor, pueden tener 18 años, pero también 10, o 5 . A lo largo del texto se emplea la palabra juventud para referenciar a las y los "Pulgarcitos", sin usar los vocablos infancia o niñez. Por esta razón, la elaboración de un diagnóstico de época expresado en estos términos, como acontecimiento, alude a unos nuevos modos de habitar la infancia en el presente, tan potentes que incluso conllevan la suspensión del término. En otras palabras, si seguimos a pie juntillas las expresiones de Serres, podremos afirmar la caída en desuso de la concepción de infancia formulada por la modernidad (Meirieu, 2010). Más allá de la edad que tengan, los modos de ser y proceder de los Pulgarcitos y las Pulgarcitas coinciden con la semántica propia de la noción de juventud, redefiniendo así las intervenciones de los adultos sobre ellos.

Si bien tenemos varios motivos para discutir las certezas formuladas por Michel Serres sobre la irreversible novedad que afecta a las formas de habitar las infancias, algo del presente trastocó el vínculo entre generaciones $y$, al tiempo que estallan los argumentos modernos sobre el tema, se perfila una invitación en perspectiva histórica para analizar las formas de pensar, entender, definir e intervenir sobre las infancias (Diker, 2008; Lobato, 2019; Marín y León Palencia, 2018; Narodowski, 1999a). De tal suerte, el enfoque histórico resulta ser una herramienta para explorar sucesos puntuales en los cuales la noción de infancia fue pensada y conceptualizada por urgencias contextuales. Justamente, activar el diálogo entre pasado y presente ayuda a revisar cómo ha variado con el tiempo la carga semántica que compuso la citada expresión.

Concretamente, en este artículo describiremos el ejercicio de reflexión que realizaron dos educacionistas argentinas contemporáneas entre sí, acerca de los modos de ser alumno/niño. Esas reflexiones dan forma a una conceptualización situada, pero también pedagógica. A lo largo del siglo xx, diferentes voces de maestras y maestros irrumpieron para arrojar saber didáctico, conceptual y empírico en torno a la condición de alumno, para lo cual enunciaron qué entendían por niño. Sin duda, preocuparse por el problema de las infancias es un desafío constitutivo del oficio docente, y las maestras que referenciamos lo ejemplifican a partir de la obra escrita que nos legaron.

Las docentes que estudiaremos son Olga Cossettini (1898-1987) y Herminia Brumana (1896-1954). Ambas tuvieron trayectorias formativas similares. Fueron muchachas nacidas en pequeños pueblos de provincia, hijas de inmigrantes italianos y debieron trasladarse de sus ciudades natales a otra para cumplimentar sus estudios de docencia. Por ejemplo, Olga 
nació en San Jorge (provincia de Santa Fe); al poco tiempo migró con su familia a Rafaela, pero para estudiar tuvo que instalarse sola en la ciudad de Coronda, donde obtuvo su título de maestra normal rural ${ }^{1}$. Por su parte, Herminia era oriunda de Pigüé, otra pequeña población emplazada en la provincia de Buenos Aires. Por lo cual, para realizar su formación como maestra, también debió mudarse y residir en Olavarría, urbe que contaba con una escuela normal ${ }^{2}$. El gesto del traslado a temprana edad asignó a ambas mujeres una dosis de libertad, una experiencia singular, pero también las volvió objeto del ojo atento del control de la época sobre las muchachas que residían separadas de sus familiares (Barrancos, 1999).

Cossettini terminó sus estudios en 1914; y Brumana, en 1916. Desde entonces, empezaron el periplo de la carrera docente que las llevó de enseñar en pueblos de provincia a ejercer los cargos de directora (en el caso de la primera) y vicedirectora (la segunda), siempre en escuelas de gestión pública y estatal. En ese trayecto, ambas se proyectaron como escritoras didácticas (Galván Lafarga y Martínez Moctezuma, 2017), que adquirieron renombre en el conjunto de productos editoriales de carácter didáctico-pedagógico (Caldo, 2018). Es oportuno mencionar que Olga se destacó como pedagoga, en tanto que Herminia lo hizo como escritora de literatura infantil, puesto que los textos que destinó para las escuelas estuvieron orientados fundamentalmente a los estudiantes y al uso en las aulas. A su vez, la pluma de Olga siempre corrió sobre problemas vinculados a la docencia; en cambio, Brumana fue una activa militante anarquista y filo-socialista que, en compañía de su esposo Juan Antonio Solari, viajó por diferentes países dictando conferencias y publicó en importantes medios de prensa, e influyó en el campo literario (como autora de cuentos, guiones de teatro y artículos de crítica sociocultural).

Si a simple vista las historias de Olga y Herminia tienen aires de familia, ambas fueron producto de un contexto social donde la tensión política del país iba en aumento, marcando especificidades regionales así como la proyección de las mujeres en el espacio público. Herminia supo capitalizar el clima social de la provincia de Buenos Aires y, más aún, el de la ciudad de Buenos Aires. Su mayor aporte de crítica social y producción de sentidos lo realizó en compañía de su esposo, reconocido político socialista, y proponiendo la maternidad como clave para la proyección social de la mujer. Entre tanto Olga, desde el interior del país, se mantuvo soltera, fiel al linaje paterno y ejerció la docencia valiéndose de las posibilidades ofrecidas por la cultura rosarina. Es meritorio explicar que Olga era hija de un inmigrante, Antonio Cossettini, que fue docente y supervisor en la provincia de Santa Fe. El padre participó del ideario masónico, bregando así por la ilustración 
de la sociedad, el librepensamiento y la laicidad, mismos principios que promovió el Estado santafesino, al menos en los años 20 y 30 (Pellegrini Malpiedi, 2020). Asimismo, la simpatía con los métodos activos fue tangible en la citada provincia, por lo cual la hija de Antonio Cossettini avanzó en una carrera segura, aunque no exenta de sobresaltos. Ella abrió intersticios en la hegemonía del normalismo para comenzar a operar desde proyectos experimentales efectivamente conseguidos con reconocimiento estatal.

Esta breve síntesis nos muestra cómo Olga y Herminia siguieron trayectorias similares, en la medida en que el clima político y los recursos de la cultura que las rodearon las remitieron a desarrollar experiencias específicas. Así, Olga dejó su marca pedagógica al amparo de los rostros masculinos del Estado santafesino (al menos entre 1930 y 1943), en tanto que Brumana se enfrentó sistemáticamente con los agentes estatales bonaerenses, recibiendo sanaciones y siempre expresándose desde las ideas anarco-socialistas que profesaban tanto ella como su compañero de vida, Solari (Jáuregui, 1956).

Sin duda, ambas fueron prolíficas productoras de pensamientos que escribieron y publicaron. En consecuencia, frecuentemente se las define como maestras intelectuales que reflexionaron sobre las prácticas de enseñanza y transformaron esos ejercicios críticos en productos editoriales. El desafío de este artículo es describir y presentar cómo a lo largo de esa producción escrita se postuló un concepto de alumno que revisa y referencia una concepción particular de niño. El análisis se construye desde la mirada docente y desde las prácticas que, en la medida en que intentan perfeccionar los modos de trabajar con los alumnos en las escuelas, dan lugar a una concepción de niñez escolarizada situada, empírica, histórica, pedagógica y también plural. Estas maestras generalmente se pronuncian sin citas bibliográficas ni referencias teóricas. Por el contrario, sostienen su decir en las prácticas y en el análisis comparativo y descriptivo de estas con el fin de mejorarlas. Es decir, ellas presentan y prescriben para las infancias que habitan en las aulas que conocen. Estos ejercicios se vuelven un antecedente que invita a pensar en las claves de época que llevan a enunciar determinados conceptos de infancia y, por ende, de alumno.

\section{Metodología}

Nos situamos en la historia cultural en perspectiva de género y en franco diálogo con la historia del libro, la lectura y la escritura (Chartier, 1999; López, 2006). Desde este registro, las reflexiones compartidas se sostienen en una lectura descriptiva e interpretativa que apunta a dilucidar saberes sobre el concepto de infancia en una serie de libros publicados bajo la autoría de Olga Cossettini y de Herminia Brumana. 
Este posicionamiento metodológico indica entender el libro como un soporte textual que permite la circulación del conocimiento. Se señala que entre el trabajo de las autoras y el propio de la edición median acciones de órdenes diferentes que, muchas veces, condicionan el contenido y que merecen ser aclaradas. Precisamente, tanto Herminia como Olga son autoras de textos madurados al calor de los registros de la experiencia docente. Por esto, el contenido dado a leer es producto del trabajo paulatino en terreno que luego es intervenido con reflexiones teóricas e incluso acompañado por prólogos escritos por terceros. A esa primera tarea prosigue la labor de edición que, en el caso de Brumana fue asumida en forma particular (Jáuregui, 1956), en tanto que Olga algunas veces recibió financiamiento del Estado o pudo publicar en editoriales universitarias (Fernández y Caldo, 2013), específicamente, en la de la Universidad Nacional del Litoral y en la de la Universidad de Buenos Aires (Eudeba-organismo del que llegó a ser autoridad). Los vínculos de sociabilidad que Cossettini supo tejer la relacionaron con destacados personajes del campo intelectual y del mundo de la política provincial. Justamente, ella se encargó de capitalizar esos lazos para hacer crecer, prosperar y conocer su pensamiento.

Ahora bien, como quedó expreso, para llevar adelante el trabajo interpretativo programado para responder a las preguntas qué, por qué y cómo estas maestras escribieron sobre la infancia; tomaremos como referencia una selección de la obra publicada. De Herminia: Palabritas (1918) y Tizas de colores (1932); de Olga, Sobre un ensayo de escuela Serena en la provincia de Santa Fe (1935), Escuela Serena: Apuntes de una maestra (1935) y El niño y su expresión (1940). La consulta de estos escritos fue posible gracias a que las obras completas de estas autoras fueron editadas. La Asociación de Amigos de Herminia Brumana, al poco tiempo de su muerte, realizó la recopilación de y publicación de sus escritos (1958). En el caso de Cossettini, fue la editora de la Asociación del Magisterio de Santa Fe (Amsafe) quien asumió la tarea (2001). Sin duda, la existencia de estas compilaciones agiliza la tarea de leerlas.

El enfoque metodológico se complementa a partir de un entramado de categorías analíticas que nos permiten ubicar a las mujeres escogidas en el marco de la cultura y de su oficio. Así cruzamos la perspectiva de género, las discusiones en torno a la pertinencia de la categoría intelectual para calificar a las maestras y los alcances del proceso de feminización de la docencia (Caldo, 2018; Fiorucci, 2016). Una vez expuestas las condiciones que facilitaron la producción de saberes de las maestras, podremos describir el contenido, la forma, el tono y la semántica empleada para definir a los niños y niñas que habitan en los alumnos y las alumnas.

Tanto Olga como Herminia fueron producto del paulatino y constante proceso de feminización de la docencia que dotó a muchas mujeres de saberes, no solo en cuanto a la lectoescritura, la ciencia y la cultura, 
sino gremiales, económicos y políticos (Morgade, 1997). Ellas supieron trazar sus trayectorias formativas en diálogo con colegas e intelectuales destacados a partir de los cuales crecieron en redes de sociabilidad y en la toma de posturas teóricas. Así, ambas fueron escritoras.

Ahora bien, ese oficio ¿las convirtió en intelectuales o en escritoras didácticas? (Caldo, 2018: Galván Lafarga y Martínez Moctezuma, 2017). Aquí, justamente, la perspectiva de género es la que nos permite discutir el carácter androcéntrico de la noción de intelectual, y preferimos definirlas como escritoras didácticas; esto es, como maestras que se abocaron a reflexionar sobre sus prácticas de enseñanza elaborando ejercicios de escritura sistemáticos vinculados a temas escolares. En este sentido, tanto las publicaciones de Brumana como las de Cossettini parten de la observación de experiencias educativas; ese registro aporta originalidad al texto.

Ambas se presentan a partir de una enunciación en primera persona que conlleva a reconocerlas como activas participantes de los quehaceres educativos. Ese mirar desde adentro, pensando y escribiendo, es parte de los saberes que la escuela produce para llevar a cabo el trabajo de transmisión de los contenidos curriculares (Terigi, 2007). Estas escritoras didácticas de primera mitad de siglo xx asumieron la labor sistemática de poner por escrito eso que pasaba en las aulas cuando se realizaba el trabajo diario. Por tratarse de ejercicios frecuentes pero personales, cada observadora orientó su mirada de acuerdo a sus principios, diálogos pedagógicos o políticos y a la sensibilidad que las distingue. Mientras que Cossettini se proyectó como parte del conjunto de voceros del escolanovismo en Argentina, reconociendo en su proceder a una línea de colegas, Brumana hizo lo propio desde su militancia social, para la que acuñó bases teóricas del anarquismo y también del socialismo. Entonces, mientras la primera presentó al pedagogo italiano escolanovista José Lombardo Radice (18791938) como "ese gran espíritu maestro (en quien) encontramos a través de sus cartas y de su obra la benéfica influencia de su sabio consejo" (2001b, p. 79), la segunda citó recurrentemente al escritor español radicado en Paraguay, Rafael Barrett (1876-1910), reconocido por su filiación anarquista. En esos diálogos fueron construyendo el marco conceptual que les permitió escribir las prácticas.

Si bien Olga escribió textos para sus colegas (no para los alumnos), sus libros fueron prescriptivos y orientativos de las prácticas educativas. En cambio, Brumana sí elaboró libros de lectura para ser tratados en clase, como Palabritas (Caldo, 2020). Sin embargo, esta última aventuró su pluma más allá del campo educativo transitando así por la novela, la crítica literaria y la crítica cultural, escritos en los que la situación de las mujeres fue tema de referencia. 
Esbozado el enfoque teórico-metodológico, presentamos los resultados que nos permiten enunciar presupuestos conceptuales sobre la infancia escolarizada.

\section{Resultados}

Como quedó explícito, analizaremos para luego comparar dos modos de definir y describir la niñez/infancia realizados por dos maestras argentinas. El ejercicio busca mostrar cómo, a pesar de que Olga y Herminia fueron formadas en escuelas normales nacionales (Rodríguez, 2019), sus lecturas, recorridos y concepciones adquirieron notables diferencias.

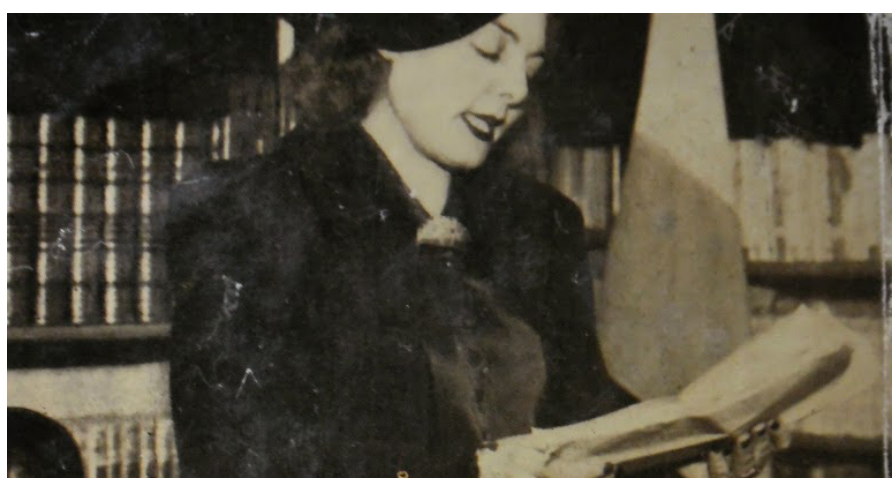

Herminia Brumana, fotografía tomada el 13 de junio de 1942 en la Plata y reproducida en el periódico La Mañana de la ciudad de Mar del Plata (19 de enero de 1957). El original puede consultarse en el Centro de Documentación e Investigación de la Cultura de Izquierdas (CeDinci), ciudad de Buenos Aires.

Herminia Brumana entendió desde temprana edad que la escritura, el ensayo crítico y los ejercicios de publicación eran parte central de un hacer que la perfeccionaba como maestra, pero más como mujer con plena conciencia social y política. De este modo, cuando aún le restaba un año para graduarse, participó en un concurso de escritura en el que obtuvo el primer premio. En 1916, la Biblioteca Popular de Olavarría lanzó un concurso de ensayos, del que hizo parte, escribiendo sobre las influencias de las bibliotecas en la cultura de los pueblos. Esa escritura primera daba cuenta del enorme conocimiento de la dama, pese a su juventud. Ya anunciaba poseer una agudeza, que perfeccionó cuando comenzó a ejercer el magisterio, para analizar las articulaciones entre las instituciones de reparto cultural y los sectores sociales más desprotegidos.

En esa dinámica, poco después de recibirse de maestra publicó un libro de lectura para los alumnos y alumnas de los grados superiores de la educación primaria, Ilamado Palabritas (1918). Hemos podido comprobar que ese texto no fue aprobado por el Consejo de Educación para su uso en 
las escuelas, lo que provocó, por un lado, los reclamos de la maestra y, por otro, el uso de este por un sector de docentes solidarios con la autora y en bibliotecas populares y personales (Caldo, 2020). Las inhabilitaciones escolares para la utilización del libro fueron las que la catapultaron al lugar de escritora de literatura infantil. Luego de esa primera experiencia frustrada, la maestra siguió publicando, pero solo volvió a incursionar en el género pedagógico la víspera de su jubilación, cuando publicó un libro de ensayos Ilamado Tizas de colores (1932). Este nuevo texto también fue financiado por la autora y reunía reflexiones sobre su experiencia escolar. En breves líneas introductorias, Brumana expresa: "Publico estas impresiones en el momento en que dejo de pertenecer al magisterio bonaerense. Mantengo viva mi fe en la escuela, a pesar de la incomprensión y la incapacidad de ciertas altas autoridades" (1958b, p. 207).

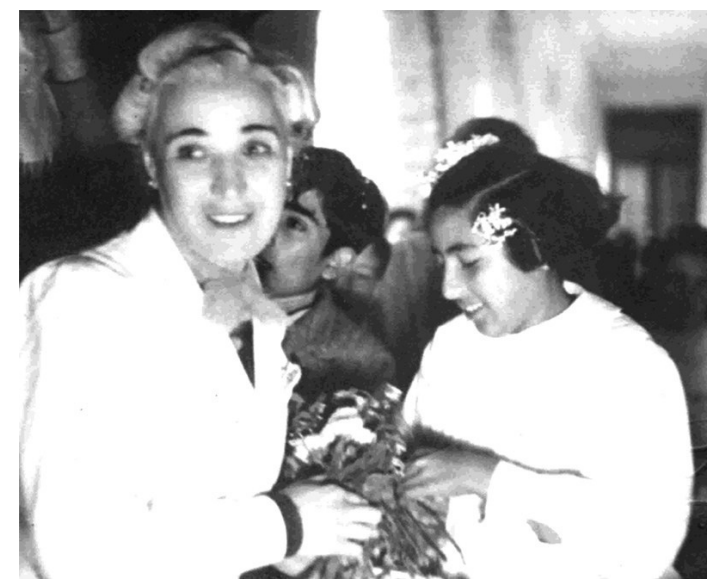

Olga Cossettini y sus alumnos en la Escuela Serena (sin referencia de fecha, se estima entre 1935-1950 sic). Vista en Archivo Pedagógico Cossettini - IRICE-UnR/Conicet.

Si bien la historia de Olga Cossettini guarda semejanza con la de Brumana, contiene sus notas de singularidad. La maestra santafesina, al posicionarse tempranamente en el escolanovismo, protagonizó una abierta batalla contra la pedagogía normalista. Su trayecto de formación aconteció en una serie de instituciones educativas simpatizantes con esa línea pedagógica. Así, pasó por la Escuela Normal de la ciudad de Coronda, luego alcanzó la dirección del Departamento de Aplicación de la Escuela Normal de Rafaela y, finalmente, adquirió un permiso especial para dar curso a una escuela experimental en la ciudad de Rosario, conocida como la Escuela Dr. Gabriel Carrasco, sita en el barrio Alberdi (1935-1950). En cada una de esas instancias afianzó y puso en práctica un modo de trabajo declaradamente escolanovista que, con el correr del tiempo, reforzó con la publicación de textos reivindicativos. 
En este artículo, nos enfocamos en tres de sus artículos. Los dos primeros, Sobre un ensayo de Escuela Serena en la provincia de Santa Fe y Escuela Serena: Apuntes de una maestra, son el resultado de la experiencia en su rol de directora del Departamento de Aplicación en la Escuela Normal de Rafaela. Ella transformó en producto editorial su sistemático trabajo de escritura de prácticas, ya fuera en forma prescriptiva, ya fuera a partir de la transcripción de las observaciones de clases. Ambas publicaciones describen una práctica singular y crítica de la pedagogía normalista. El tercer libro, El niño y su expresión, es posterior, pero continúa esa línea de trabajo, esta vez en la ciudad de Rosario. En la Escuela Serena rosarina se Ilevaron a cabo misiones culturales, entre las cuales se destacó una que consistió en montar una muestra de obras de sus alumnos y alumnas en el Museo Municipal de Bellas Artes Juan B. Castagnino. Los niños y las niñas de la escuela de la señorita Olga se convirtieron en artistas y autores. Justamente, el libro seleccionado recupera tanto la conferencia dictada por Olga como el trabajo de los pequeños en ese marco específico (Fernández y Caldo, 2013).

A diferencia de Brumana, Olga Cossettini no escribió textos para sus alumnos ni tampoco incursionó con su pluma en temas que escaparan a los quehaceres educativos escolarizados. Sus escritos recuperaron la experiencia docente y apuntaron a ser una hoja de ruta para la inserción de la corriente escolanovista en las escuelas argentinas.

Tanto Olga como Herminia se expresaron en términos críticos con respecto a las prácticas pedagógicas basadas en los principios del normalismo. No obstante, mientras que la primera lo hizo desde un registro pedagógico, la Escuela Nueva, la segunda lo abordó desde su militancia en el anarquismo y mediante su simpatía con el socialismo. Desde esos lugares, contemplaron la experiencia escolar y allí situaron a sus alumnos y alumnas, quienes necesariamente habitaban en cuerpos de niños y niñas. Al decir de Mariano Narodowski: "niño y alumno se corresponden existencialmente en un mismo ser pero epistemológicamente constituyen objetos diferentes" (1999b, p. 26). Por lo cual, en estas páginas hablaremos de niños y niñas recuperando voces preocupadas por los alumnos y las alumnas.

Herminia Brumana expresó:

más que al cerebro, para el corazón de los niños es mi obrita. Convencida de que el cerebro se llena por sí solo, viviendo simplemente; pero el corazón es preciso llenarlo desde pequeño. Si fuera un libro para niños, sin ser para escolares hubiera sido más sencillo; todas las ideas en forma de cuentos amenos. Pero como ha de estar el maestro cuando lean, él se encargará de comentarlos, de hacerlos pensar alrededor de cada lectura. (1958a, p. 14) 
En esta lógica, un niño se hace alumno cuando entra en relación con un maestro que lo sustrae de su cotidianidad y lo invita a pensar con el firme propósito de educar su corazón. ¿A qué se refiere la autora con esta expresión? Para ella, se actúa de corazón cuando se es sensible a las desigualdades que atraviesan la sociedad y generan violencias, desamparo, hambre, maltratos, humillaciones y carencias. El ojo del docente debe saber desentrañar esas tramas que se esconden en la mirada de los pequeños. Allí, en su hacer sensible descubre los pesares. Además, la autora supone que los niños son inocentes por naturaleza. Y esas características son las que los vuelven transparentes y poco atentos a los engaños. Ella escribe: "Pobrecitos chicos de mi corazón: no se necesita ser adivina ni gran psicóloga para saber cuándo mienten. La inocencia tiene la mirada tan clara, tan pura, que la más insignificante sombra la empaña" (Brumana, 1958b, p. 208).

Sin embargo, cuando Brumana escribe para sus alumnos, lejos de interpelar a un lector homogéneo, dirige su mensaje hacia un sector del estudiantado. Entonces explica:

Eso pensáis vosotros, que tenéis un hogar cómodo. Pero escuchadme bien amiguitos: hay otros chicos que en estos días de frío, cuando la maestra dicta los deberes, en vez de ponerse contentos tienen ganas de Ilorar... Van despacio por la calle. Al Ilegar a la casa, no encuentran, como vosotros, el té caliente servido por la mamá. (1958a, p. 13)

Ese "vosotros" interpela a los niños y niñas de clase media o alta que desconocen los modos de vivir de otros y otras. Ella se ocupa de transformar las diferencias sociales en contenido escolar para que desde el aula se las pueda problematizar. Con palabras sencillas, explica que existen al menos dos modos de vivir la niñez: con alimentos, afectos, cuidados y contención o con trabajo, maltrato, hambre y carencias. Célebre resultó un pequeño ensayo Ilamado Los deberes, donde la autora se presenta ejerciendo como directora y, en ese rol, recibe a un alumno para ser sancionado. El niño no cumple con los mandatos escolares: estudiar y hacer los deberes. Entonces, lo interroga y al hacerlo descubre que el muchacho trabaja porque su padre está internado por causa del consumo de alcohol. La mujer se siente enmudecer y detiene el interrogatorio. Literalmente afirma: "tengo que justificar mi autoridad en la escuela, tengo que intentar siquiera algo para decirle a la maestra que este alumno me ha prometido cumplir con sus deberes" (Brumana, 1958b, p. 231). Mientras hace un pacto con el niño sancionado, piensa: "Ustedes no tienen ni el deber de ser buenos, porque les han negado el derecho a la felicidad" (p. 231).

Esa concepción de infancia inocente, plena, lúdica e ingenua se enrarece cuando la autora despliega su observación aguda sobre las impresiones que las condiciones materiales de la existencia dejan en los trayectos biográficos. En otro de sus ensayos describe lo visto durante un desfile escolar: 
Niños y niñas (estas últimas disfrazadas de argentinas con moños celestes en la cabeza) soportan con admirable resignación el espectáculo. La democracia, la igualdad a la que se tiende haciéndoles vestir a todos el guardapolvo blanco, cae al primer vistazo del observador. (Brumana, 1958b, p. 220)

Los y las participantes "soportan" las órdenes recibidas desde la escuela y las ejecutan con docilidad. La mirada atenta reposa en el vestuario primero de las niñas, a quienes advierte disfrazadas con moños, luego en el símbolo de la igualdad escolar por excelencia: el guardapolvo blanco. Desde inicios del siglo xx en Argentina, esta prenda fue escogida como uniforme de uso común tanto para alumnos como para los maestros. Sin embargo, más que una solución efectiva, Brumana advierte en ello una máscara que oculta las distinciones sociales que, sin embargo, siguen haciendo síntoma en el calzado (Caldo, 2014; Dussel, 2000). Se pregunta:

¿Puede el guardapolvo salvador igualar los piececitos de estos niños, calzados unos con el flamante zapatito charolado y cubiertos otros con la gastada zapatilla que mal disimula la media remendada? ¿Puede el guardapolvo blanco salvador igualar todas estas caritas, rosadas y relucientes de bien nutridos organismos unas, y amarillentas y pálidas, otras?... (Brumana, 1958b, p. 220)

El guardapolvo cubre, mas no da solución alguna al problema de la marginalidad social. Pero, y aquí la autora deja al descubierto su creencia en una infancia pura y carente de conocimientos incluso sobre los dramas sociales, "Una sola cosa los iguala: ellos no saben lo que dicen esos hombres que hablan. Vienen porque los mandan y porque tienen la íntima esperanza de que al final del suplicio repartirán caramelos" (Brumana, 1958b, p. 220).

El guardapolvo salvador, no salva, pero la condición de niño o niña tiene un potencial que, bien encaminado, puede dejarlos al margen de los daños de las intervenciones de las políticas en general y de las educativas en particular. En este punto, el lugar del adulto que mira viendo y actúa con tacto y corazón es crucial. Hay una condena social de orden material que una maestra puede evitar e incluso capitalizar en los niños para hacerlos escurridizos, sensibles y atentos sin sucumbir ante la crueldad de la sociedad. Por eso apuesta a generar contenidos críticos de la realidad social, a que sus estudiantes tramiten la sensibilidad en cuanto al cuidado y al reconocimiento de los otros y, además, facilita el juego.

Brumana invita a sus alumnos y alumnas a generar momentos lúdicos en los que puedan gestar claves críticas e igualitarias para vivir en sociedad, entonces dice: 
Si tienes hermanitos mejor; serán tus compañeros de trabajo, tus socios. Pero óyeme bien: tus socios, no tus peones. La chacrita será de todos. (Brumana, 1958a, p. 14)

En esta cita, presenta un juego que apunta a colectivizar las tareas, los espacios y las herramientas. Sin duda, prima la idea de educar a los niños en el trabajo cooperativo, donde no hay dueños ni autoridades, sino varones comprometidos con la producción de bienes que los beneficiarán como parte de un colectivo. Dar lugar a escenas auténticas de igualdad, es la meta de la maestra. La actividad lúdica entretiene a la vez que forma y entrena a sus participantes en prácticas sociales, pero tiene su adaptación para el caso de las niñas:

\begin{abstract}
Si tienes una hermanita, le cedes un pedacito de tierra para que ponga flores... Yo sé otro juego también, pero es más propio para niñas. Es el juego del gallinerito. Para ese tienes que pedir a tu mamá unas gallinas. Las cuidaras, les darás de comer y pondrás agua limpia todos los días en los tachitos. (Brumana, 1958a, pp. 14-15)
\end{abstract}

En las prescripciones de Brumana, la diferencia entre los sexos queda naturalizada. Mientras que los varoncitos cultivan la tierra y dirimen en torno a ello, las niñas se encargan del jardín y de criar los pollitos. Los niños se abocan a la tarea productiva, las niñas a la crianza/maternaje. En este sentido, pese a defender la co-educación, desde el juego se refuerza el lugar doméstico de la mujer. Entonces, Brumana denuncia que las diferencias materiales realizan una partición de la infancia entre niños alimentados, deseados, amados y cuidados y otros vulnerados, hambrientos y descuidados. Empero, sus aportaciones enfatizan la diferencia entre niños fuertes, trabajadores y encargados de la producción y niñas frágiles y domésticas. En este punto, estalla la posibilidad de pensar un concepto de niñez en singular.

El planteo de Olga Cossettini también parte de considerar a la niñez como alumnos, pero su entrada analítica adquiere singularidades. A ella le preocupa el lugar quieto, pasivo, mecánico y silenciado que la pedagogía normalista otorgó al alumno. De esta manera, aquí podría pensarse en una partición de la infancia ya no marcada por las condiciones materiales de la existencia, sino por las intervenciones pedagógicas que guían su desarrollo hacia la adultez.

Y así como el positivismo penetró en la cultura, penetró en la escuela y programas y libros y métodos reflejaron el positivismo de la época utilitario y práctico... La preparación del maestro descansó absolutamente sobre ese mecanismo con fe ciega en el método... Pero felizmente el espíritu se sobrepone a la materia y el maestro de verdad intuyó el acto de educar como compenetración de las almas... 
En esta dinámica, el punto crítico de la escuela no está en ser un aparato que invisibiliza desigualdades, sino en ser un espacio que apaga el movimiento creativo de los niños gracias a la sistemática aplicación de metodologías de corte positivista. En otras palabras, el problema reside en el recurrente disciplinamiento que confina a los niños a la inacción, inhibiendo la expresión y la creatividad. En 1940, Olga afirmó:

\section{Con los compañeros de tarea hemos llegado a un común acuerdo y la práctica, con sus resultados, nos ha dado amplia aprobación de que para llegar al alma del niño, es necesario que el maestro modifique su impe- rativo pedagógico; es él, siempre él, quien imprime a la clase artificiosi- dad, el que crea ambiente frío, clima doctoral, tan opuesto al natural del niño, emotivo, cálido, sincero siempre. (2001c, p. 193)}

Los supuestos que Olga Cossettini ordenó para pensar la niñez van combinándose al calor de su aguda crítica a la pedagogía normalista. Ella entiende que en su época eran los pilares filosóficos-pedagógicos tradicionales y positivistas los que se utilizaban para conceptualizar al niño escolarizado. Así, se lo entendía como una tabula rasa que los maestros debían cargar de contenidos relativos a la vida, la ciencia y la cultura. El niño devenido alumno era un gran receptor pasivo de los contenidos impartidos. No obstante el consenso adquirido por esta tendencia, muchos educacionistas comenzaron a cuestionar esa pasividad, entre ellos, Olga. De este modo, se pensó en una oferta educativa que, situando la actividad del niño como eje del trabajo, apuntara a la libertad, la creatividad y la expresión.

En efecto, de acuerdo con Olga, los niños no eran seres incompletos a la espera de ser "llenados" en su paso por la escuela. Por el contrario, desde su nacimiento, el infante demostraba tener una unidad interior que — unas veces Ilamada alma, otras Ilamada espíritu- debía ser desarrollada por una serie de intervenciones del adulto (en la escuela esta función debía cumplirla el maestro-guía). De esta manera, más que imprimir conocimientos, la "señorita" debía encauzar esa interioridad para alcanzar su desenvolvimiento y perfección. Como se puede observar, Cossettini deposita una sustantiva confianza en el vínculo alumno-maestro, así como en la capacidad de todos los infantes (más allá de sus condiciones económicas o cognitivas) para alcanzar su máximo nivel de expresión y creatividad.

Precisamente, en Escuela Serena: Apuntes de una maestra, afirma que los niños son "seres vivos dotados de alma" (Cossettini, 2001b, p. 158) y que, en el correcto desarrollo de ese espontáneo y creativo espíritu descansa la "esperanza" (p. 180) de una sociedad justa. Para la maestra, el niño requiere un desarrollo doble: social y espiritual (2001c). Mientras que el primero es objeto del Estado y sus políticas públicas en general, el 
segundo es específico de la Escuela con sus intervenciones pedagógicas-escolanovistas. Entonces, los quehaceres del maestro escolanovista tuvieron como base el respeto por el espíritu de los niños, siempre vulnerado por la pedagogía positivista.

Las reflexiones escritas por Olga determinan dos señalamientos teórico-prácticos para los maestros. El primero entiende la infancia como una etapa de plenitud en la cual el alma se presenta en su máxima espontaneidad y creatividad. El segundo pone en valor el oficio del maestro de verdad, justamente aquel que entiende que la educación debe respetar la libertad infantil y guiarla por los carriles de la cultura, sin corromper su naturaleza.

Cuando Cossettini presenta el proyecto de Escuela Serena implementado en la ciudad de Rafaela, bajo el subtítulo "Alumnos" explica: "Trabajamos con niños normales, sanos, en general disciplinados" (2001a, p. 30). La maestra asienta por escrito un supuesto clave de la educación primaria: los alumnos son niños, y no cualquier niño, son normales. Entiende como componente de la normalidad la buena salud y el buen comportamiento general. Pero, continúa diciendo: "Clases mixtas de 30 y 35 alumnos bajo la dirección de una maestra. Consideramos necesaria la coeducación de los sexos, con proyección hacia la vida futura" (2001a, p. 30).

Pese a que la coeducación fue un mandato establecido por la Ley de Educación Común 1420 del año 1884, aún en 1935 los maestros se encuentran en la necesidad de argumentar en su favor (Caldo, 2019). Olga es clara al respecto: niños y niñas juntos aprenden mejor $y$, con sus clases mixtas, la dinámica escolar adquiere una armonía original que destaca:

Habiendo orientado la educación hacia el sentido de despertar los intereses naturales de los niños, el desenvolvimiento fue espontáneo y natural.

Debo hacer resaltar el espíritu de colaboración y de ayuda mutua que siempre existió entre los alumnos de ambos sexos y el ambiente de afecto y de estima que ellos han creado. (Cossettini, 2001a, p. 30)

Para ella, la infancia es una etapa de plena actividad donde la inocencia convive con la espontaneidad, la gracia, el bullicio, la expresión y la agilidad. Los niños se mueven, corren, saltan, gritan y se ríen. Esa plena actividad es la razón de ser de la infancia, más allá de las circunstancias del contexto, sociales o económicas que aquejen a cada alumno en particular. La maestra está convencida de que la pedagogía escolanovista propone una caja de herramientas que ayuda al desarrollo del alma infantil. En su lectura analítica, parte de situar la escuela en su contexto:

Nuestra escuela está ubicada en el límite de la ciudad y el campo... Pero la brisa de ese río amigo, el verdor de sus barrancas, el canto 
de los pájaros, nos traen armonías todas las mañanas y los niños que bajan de los ranchos, de las casitas obreras y de las viviendas mejores, pueblan la escuela de bullicio hasta el sol de la tarde. Su ritmo es de juego y de trabajo. Tiene expresión clara, sonríe a la vida... (Cossettini, 2001c, p. 191)

Su escuela está situada en la periferia de una ciudad, Rosario, en vías de modernización. Habitar en los bordes crea puntos de contacto con experiencias nuevas. De acuerdo con sus palabras, sus alumnos son los que no llegan al centro de la ciudad, pero, en esos trayectos diferentes, poseen una singularidad que ella está dispuesta a capitalizar. Su propuesta educativa ofrece un espacio-tiempo de suspensión de las diferencias para que los invada la alegría de ser parte de una comunidad educativa.

en esa sociedad que es la escuela, el niño se mueve, actúa, es una célula viva, ser individual nutrido del elemento social que es la clase, la comunidad escolar. Al actuar adquiere conocimiento de sí, de sus fuerzas internas, y forma su personalidad que cada día se manifiesta con perfiles propios, originales, distinto al de los demás. (2001c, p. 191)

Al privilegiar el movimiento, la creatividad y las inquietudes de los educandos, la escuela de la señorita Olga se transformó en un lugar preferido por los niños. La maestra, en su rol de directora, narra cómo muchos de sus alumnos, pese a cambiarse de barrio, solicitaban a sus padres que los siguieran enviando a la escuela del barrio Alberdi:

Rodolfo Vinacua de 14 años y de $6^{\circ}$ grado, niño proletario que cruza toda la ciudad para venir a la escuela, Rodolfo que podríamos clasificar de super-dotado por su excepcional inteligencia, afinada sensibilidad y definido carácter, Rodolfo que al igual que Lucinda, comparten los afanes del aula y toman la dirección de la clase. (Cossettini, 2001c, p. 204)

La pedagogía escolanovista consideraba al niño como un espíritu expresivo por naturaleza. La propuesta educativa buscaba explorar e incentivar los intereses naturales del alumno más allá de sus condiciones de existencia. Esta afirmación fue plasmada por Olga Cossettini en su libro Escuela Serena: Apuntes de una maestra, donde explica: "las maestras comprendieron que [...] el alma del niño, es un cofre sutilísimo que debe abrirse a la vida, como se abre la flor, sin tocarla y empezaron a buscar en la naturaleza el secreto" (2001b, p. 79). Ella reivindica un método de enseñanza activo que propicie el desarrollo del niño en contexto y en libertad. Puesto que no hay nada en él que no sea pura expresión, el maestro debe desarrollar el espíritu de sus alumnos, pero conservando su alma infantil. En consecuencia, los temas, lejos de ser impuestos, serán el resultado de una actividad constante y dialogada. La maestra, con cuidado corrige, sostiene Olga, pero sin hacer sentir demasiado su influencia. 
Entre sus estrategias didácticas propone la aplicación del juego y del arte (las Bellas Artes: la pintura, la música clásica, etc.). Disparadores que las docentes pondrán a disposición de sus alumnos a los fines de desarrollarles el espíritu. Con relación al juego Olga sostuvo: "El juego constituye la vida del niño. Él es un creador que crea su propia vida espiritual naciente y no admite ni jueces ni críticos [...] jugando va adquiriendo poco a poco la intuición de las cosas" (2001b, p. 82). A continuación, a partir de la escritura de algunas líneas, se pasa a describir una actividad lúdica desarrollada por los infantes:

Por ejemplo, se han reunido en la cocina. Un grupo está ocupado en la compra de verduras en un puesto improvisado del mercado. Discuten el precio y pagan. La "mamá" y la "hijita" trabajan preparando la sopa. El caldo hierve sobre el fuego y mientras se cuece la verdura o los fideos, lavan los enseres que han sido usados, preparan la mesa, Ilega el "papá" del trabajo y almuerzan. (2001b, p. 162)

Aquí se observa cómo el juego, además de resultar una estrategia didáctica dirigida a desarrollar, en este caso, el lenguaje de los estudiantes, también prescribe el sistema de valores y roles sociales que la cultura moderna demanda para los sexos. En este punto se plasma una similitud con la asignación de valores que Brumana, antes citada, prescribía para las niñas.

Por otro lado, el impulso que la Escuela Nueva le ofrece al niño para su desenvolvimiento creador en todas las manifestaciones del arte es producto de la síntesis entre la naturaleza del alumno y el amor brindado por el maestro. Así, para Olga, el espíritu espontáneo de sus alumnos se manifiesta a partir de la producción artística, pero a la vez guiado por la presencia de una conmoción afectiva causada por la imaginación y los lazos afectivos.

El maestro sabe, sin embargo, que el niño es un ser creador; lo han comprobado en miles de casos, diariamente, en cada momento en sus alumnos, en cada minuto del día, cuando escribe algo independiente del tema impuesto; cuando dibuja en libertad, cuando modela, cuando construye, cuando habla. (Cossettini, 2001c, p. 195)

El recurso del arte como estrategia didáctica demuestra la concepción de una infancia, además de activa y creativa, sensible. En recurrentes apartados de sus libros, Olga hace referencia al perceptivo interior de sus alumnos y alumnas. En ocasiones, su desarrollo lo asimila con el crecimiento de una flor. Así, como al florecer, los pétalos del capullo van abriéndose y dejando al descubierto su centro, los niños estimulados por la contemplación y puesta en acción estética, van exteriorizando su interior. El arte resulta, en la obra de Olga Cossettini, una usina de libre expresión que le permite al niño crecer y orientarse a la adultez. 
Por último, la coeducación es objeto de prescripción constante. Para Olga, el trabajo colectivo más allá del sexo de los alumnos y las alumnas fomenta sentimientos como la solidaridad y la colaboración mutua que "los prepara para la vida social" (Cossettini, 2001b, p. 99). En oportunos apartados de sus libros, se refiere al trabajo horizontal en grupo, en donde resulta difícil discernir cuál de los integrantes cumple el papel de "líder". En ese aprender juntos, las almas de los niños se unen en un fraterno diálogo de respeto, ya que no intervienen las lógicas competitivas o comparativas del mundo adulto.

Sin embargo, en ese ejercicio de preparación para el mundo adulto se reproducen los roles de distribución socio-genéricos de la modernidad: “Roberto es el albañil [...] Está trabajando en el patio con la ayuda de Hugo y Miguel; piensan construir una casa [...], las niñas que son espectadoras anotan en forma de diálogo lo que observan" (2001b, p. 100). Aquí, al igual que en el juego, mientras que a los varones corresponde el trabajo manual y más rudo, para las niñas queda la contemplación. Esto demuestra que la libertad y el rasgo activo de los infantes responden a las diferencias entre los sexos.

Finalmente, de acuerdo con los escritos de Olga Cossettini, en la Escuela Serena transitó una infancia libre, creativa, sensible, solidaria (aunque con marcas de género) y capaz de alcanzar su perfecto desarrollo pese a las condiciones contextuales pero dependiente de las intervenciones pedagógicas que reciben.

\section{Conclusiones}

"La escuela transmite un saber que no produce y, para poder llevar adelante ese trabajo de transmisión, produce un saber que no es reconocido como tal", afirma Flavia Terigi (2007, p. 99). Ese "saber no reconocido" circula en las aulas, en las reuniones de maestros y maestras y, en el caso de las educacionistas objeto de este artículo, en numerosos escritos que fueron conservados gracias a la intervención de la imprenta. Esos saberes escolares, al tiempo que describen las prácticas situadas, apuntan a perfeccionarlas y, en esa cadencia, van generando conceptos elaborados entre la experiencia y los presupuestos teóricos (a veces implícitos). Entre esos presupuestos, la noción de alumno y su relación con la infancia/niñez es inevitable. Es decir, ¿quiénes son nuestros alumnos? es una pregunta de crucial valor pedagógico que todo docente, incluso Herminia y Olga, formula y responde.

Precisamente, las respuestas de nuestras dos maestras llevan marcas de sus trayectos formativos. Pero, si bien ambas fueron maestras normales, sus proyecciones como educacionistas tuvieron singularidades $y$, en esa dinámica, encontraron modos propios para pensar y definir a los niños y 
las niñas. Olga, la santafesina, trabajó en sintonía con un Estado provincial que acompañó su propuesta pedagógica al punto de darle carácter experimental e incluso financió sus publicaciones. Brumana, en cambio, fue la maestra recurrentemente sancionada que supo tallar intersticios para permanecer en su rol docente. La primera se proyectó exclusivamente en el campo pedagógico y desde allí pensó a sus alumnos, en tanto que la segunda situó a la escuela en el contexto social y propuso tanto a los docentes como a sus alumnos que se piensen y sientan viviendo en sociedad y siempre capitalizando los recursos de la cultura. Ella apela al constante consumo de cultura (cine, teatro, idiomas, prensa, paseos, etc.). En síntesis, Olga fue una pedagoga escolanovista, mientras que Herminia fue una militante anarco-socialista y, con ese compromiso, fue autora de textos de crítica social, política y cultural.

Pese a estas sustanciales diferencias ideológicas, ambas partieron de un reconocimiento tácito: el alumno/la alumna de la escuela primaria es un(a) niño/niña. Ellas no demoraron la escritura en la reflexión sobre la distancia semántica que separa al alumno del niño. Por el contrario, establecen un diálogo desde las urgencias de la observación. El niño es inocente, bueno y maleable por naturaleza. Así, sobre esa aparente homogeneidad conceptual van desglosando diferencias. Entonces, mientras que Olga brega por el tratamiento en clave pedagógica del alma y de la sensibilidad de los niños obturada por la impronta del normalismo, Brumana entiende que los agentes de las escuelas deben percatarse de las diferencias materiales que hacen mella en la sociedad y operar en relación a salvaguardar a los niños de la crueldad de la vida cotidiana. Ella no quiere una escuela que opere desde una ilusión de igualdad, sino que trabaje para devolver la infancia a aquellos niños/niñas a los que la desigualdad social se la hurtó.

Las dos maestras ponen en tensión la homogeneidad del niño escolarizado. Para Olga Cossettini existen niños pasivos, disciplinados y sumisos producto de las pedagogías tradicionales, pero también hay otros que mantienen su espíritu activo, creativo y libre a pleno, gracias al trabajo de los maestros de verdad, los docentes formados en el escolanovismo. En esta lógica, la línea de argumentos es claramente pedagógica. En cambio, para Brumana, la escuela trabaja sobre el desconocimiento de las desigualdades sociales. Estas últimas son las que determinan que haya niños plenos y otros que tuvieron que renunciar a la infancia por causa de las carencias materiales/afectivas. En esta sintonía vuelve a ser relevante el trabajo de un maestro de corazón, con la suficiente sensibilidad para operar sobre las ilusiones, tristezas y violencias sobre los niños.

Entre el pensamiento de Brumana y el de Cossettini media una concepción de escuela diferente. Para esta última, la escuela, tal como ella la formuló en su proyecto de escuela experimental (Rosario 1935-1943), era un espacio para la suspensión de las diferencias sociales. Sostenemos 
esta afirmación con la referencia de Maarten Simon y Jan Masschelein, por cuanto ellos entienden que una característica de "lo escolar" es la suspensión de los condicionamientos de productividad social (2014, pp. 33-34). En otras palabras, la escuela ofrece un tiempo despojado de determinaciones a los fines de vincular a sus agentes con el conocimiento. Así, los niños ingresaban al tiempo escolar de la Escuela Serena para expresarse y crear. Los maestros estaban ahí para acompañar ese desarroIlo expresivo. Por el contrario, Brumana entiende que la escuela oculta y enmascara las diferencias sociales. Ella percibe que la escuela insiste en cooperar con esos ejercicios de sustracción de la niñez cotidianos. Estas lecturas son un antecedente directo de quienes van a definir a la escuela como aparato transmisor de la ideología del Estado (Cerletti, 2008).

Sin dudas, la formación de Brumana proviene de la filosofía política, en tanto que Cossettini se nutre del discurso pedagógico neto. La primera milita y, en ese hacer, construye saberes; la otra es directora y dialoga con sus colegas (maestros y pedagogos). Ese herramental teórico es lo que referencia esas proyecciones tan disimiles sobre la niñez, pese a haber sido formadas en las mismas escuelas. No obstante, ambas insisten en defender la escuela como un espacio de transformación social y de consolidación de un alumno/niño. Ellas reconocen en los maestros de verdad, en el caso de Cossettini, o de corazón, para Brumana, la posibilidad de lograr una sociedad justa e igualitaria.

Por otra parte, tanto Olga como Herminia defienden la coeducación. Olga parece ser más enfática en sus exigencias respecto a ello, niños y niñas en las aulas educándose juntos. Sin embargo, las dos van a pensar en las tareas contemplativas y de crianza para las niñas, mientras que los varones asumen el lugar activo de la producción.

De cara a nuestro presente, los Pulgarcitos de antaño fueron niños y niñas. Nuestras maestras emplean la expresión niño/niña para referenciar a los sujetos que se cobijaban bajo el rótulo de alumno/alumna. Por su época, siempre se expresan en un universal genérico que lleva bajo su capa la coeducación resuelta en términos patriarcales y heteronormados. Ese universal genérico solo se altera cuando prescriben saberes relativos al sexo femenino (estética, economía doméstica, saberes relativos a la puericultura, etc.). Desde el terreno, las maestras discuten qué es un niño escolarizado, complejizan los planteos homogéneos, devolviendo así los modos de habitar la infancia a sus condiciones de posibilidad históricas. Un niño es en contexto, y es la dinámica de esos contextos la que habilita siempre el plural. Justamente, el enfoque histórico permite descubrir a las maestras produciendo saberes en y para las escuelas y, en consecuencia, sobre las infancias escolarizadas, ni singulares, ni quietas, sino dinámicas, sensibles y situadas. 
El análisis que esbozamos, lejos de agotar la reflexión sobre el pensamiento de estas maestras, apuntó a mostrar el compromiso y la capacidad de conceptualizar desde el territorio de las educadoras de antaño. Estos ejercicios nos habilitan para afirmar que, vista desde la escuela, la infancia siempre es plural, en construcción, dinámica y demandante de constantes ejercicios de actualización conceptual y metodológica. En consecuencia, el análisis histórico adquiere valor, como hoja de ruta para trazar planes para pensar las infancias en las escuelas presentes y futuras.

\section{Referencias}

Barrancos, D. (1999). Moral sexual, sexualidad y mujeres trabajadoras en el período de entreguerras. En F. Devoto y M. Madero (dir.), Historia de la vida privada en Argentina: La Argentina entre multitudes y soledades. De los años treinta a la actualidad (pp. 198-225). Taurus.

Brumana, H. (1958a). Palabritas. En H. Brumana. Obras completas (pp. 11-38). Edición Amigos de Herminia Brumana.

Brumana, H. (1958b). Tizas de colores. En H. Brumana, Obras completas (pp. 205-253). Edición Amigos de Herminia Brumana.

Caldo, P. (2014). La mujer que habita en la maestra: Sensibilidad, estética, prescripciones estatales y prácticas de consumo. En P. Pineau (dir.), Escolarizar lo sensible: Estudios sobre estética escolar, 1870-1945 (pp. 251-288). Teseo.

Caldo, P. (2018). Tizas y apuntes: Costumbres en común. Maestras, libros y prácticas de enseñanza en la Argentina de 1930. En F. Fiorucci y L. G. Rodríguez (comps.), Intelectuales de la educación y el Estado: Maestros, médicos y arquitectos (pp. 115-140). Universidad Nacional de Quilmes.

Caldo, P. (2019). Género. En F. Fiorucci y J. Bustamante Vismara (coords.), Palabras claves en la historia de la educación argentina (pp. 179-184.). Unipe Editorial Universitaria.

Caldo, P. (2020). Trabajo docente. Trabajo intelectual. Herminia Brumana, Argentina 1918-1935. En G. Queirolo y M. S. Zárate Campos (Eds.). Camino al ejercicio profesional: Trabajo y género en Argentina y Chile (siglos XIX y XX). UHA-Ediciones.

Cerletti, A. (2008). Repetición, novedad y sujeto en la educación: Un enfoque filosófico y político. Del Estante.

Chartier, R. (1999). Cultura escrita, literatura e historia: Conversaciones con Roger Chartier. Fondo de Cultura Económica.

Cossettini, O. (2001a). Sobre un ensayo de Escuela Serena en la provincia de Santa Fe. En O. Cossettini y L. Cossettini. Obras completas (pp. 11-73). Ediciones Amsafe. 
Cossettini, O. (2001b). Escuela Serena: Apuntes de una maestra. En O. Cossettini y L. Cossettini. Obras completas (pp. 75-180). Ediciones Amsafe.

Cossettini, O. (2001c). El niño y su expresión. En O. Cossettini y L. Cossettini. Obras completas (pp. 181-253). Ediciones Amsafe.

Diker, G. (2008). ¿Qué hay de nuevo en las infancias? Universidad Nacional de General Sarmiento.

Dussel, I. (2000). Historias de guardapolvos y uniformes: sobre cuerpos, normas e identidades en la escuela. En S. Gvirtz (comp.), Textos para pensar el día a día escolar (105-132). Santillana.

Fernández, S. y Caldo, P. (2013). La Maestra y el museo. El Ombú Bonsai.

Fiorucci, F. (2016). País afeminado, proletariado feminista. Mujeres inmorales e incapaces: la feminización del magisterio en disputa (1900-1920). Anuario: Historia de la Educación, 17(2), 120-137.

Galván Lafarga, L. E. y Martínez Moctezuma, L. (2017). Dos maestras: María M. Rosales y Ana María Valverde, autoras de la colección de lectura Rafaelita. En L. E. Galván Lafarga (dir.), Maestras urbanas y rurales, siglos xix y xx. Tomo 3 (pp. 67-102), Inehrm.

Jáuregui, J. F. (1956). "Herminia C. Brumana, maestra en Pigüée" [disertación radial]. Fondo Bibliográfico Herminia Brumana, Centro de Documentación e Investigación de la Cultura de Izquierdas, Fondo Documental Herminia Brumana.

Lobato, M. (2019). Infancias argentinas. Edhasa.

López, O. (2006). La maestra en la historia de la educación en México: contribuciones para hacerlas visibles. Sinéctica, 28, 4-16.

Marin, D. y León Palencia, C. (2018). Infancia: Balance de un campo discursivo. Universidad Pedagógica Nacional.

Meirieu, P. (2010). Una llamada de atención: Cartas a los mayores sobre los niños de hoy. Ariel.

Morgade, G. (1997). Mujeres en la educación: Género y docencia en la Argentina 1870-1930. Miño y Dávila.

Narodowski, M. (1999a). Después de clase: Desencantos y desafíos de la escuela actual. Novedades Educativas.

Narodowski, M. (1999b). Infancia y poder. La conformación de la pedagogía moderna. Aique.

Pellegrini Malpiedi, M. (2020). Cuerpos, géneros, sensibilidades y emociones: La propuesta pedagógica de Leticia Cossettini. Rosario, 19351950. [Tesis de doctorado, Universidad de Buenos Aires]. 
Rodríguez, L. G. (2019). Cien años de normalismo en Argentina (18701970). Apuntes sobre una burocracia destinada a la formación de docentes. Ciencia, Docencia y Tecnología, 30(59), 200-235. https:// doi.org/10.33255/3059/690

Serres, M. (2012). Pulgarcita. Fondo de Cultura Económica.

Simon, M. Masschelein, J. (2014). Defensa de la escuela: Una cuestión pública. Miño y Dávila.

Terigi, F. (2007). Exploración de una idea: En torno a los saberes de lo escolar. En R. Baquero, G. Diker y G. Frigerio (Coords.), La forma de lo escolar (pp. 99-118). El Estante. 